\title{
Use of the Ultrasound to Determine the Level of Lumbar Puncture in Pregnant Women
}

Giovani de Figueiredo Locks, TSA, M.D., Maria Cristina

Simões de Almeida, TSA, M.D., Amanda Amaro Pereira

\section{INTRODUCTION}

Neuroaxis block represents the most common technique indicated for cesarean section, since the incidence of maternal morbidity and mortality and neonatal depression is lower than that of general anesthesia ${ }^{1}$. Among regional anesthetic techniques, subarachnoid blocks promote shorter time between induction and delivery and better quality of blockade than epidural blockades ${ }^{2}$. Therefore, subarachnoid blocks have become the technique of choice for elective cesarean sections among us.

Traditionally, an imaginary line connecting both iliac crests, called Tuffier's line, is used to determine the level of the lumbar puncture. In theory, this line crosses the spine at the level of $L_{4}$ or $L_{4}-L_{5}$ space. A puncture below $L_{3}-L_{4}$ would be below the level of the medullary cone, providing safety to the method. However, it has been demonstrated that anatomical reference has an abnormal distribution and this determination can be inaccurate in a large proportion of patients ${ }^{3}$. Incorrect determination of the puncture level is a known risk factor for medullary cone injury in spinal blocks. The American Society of Regional Anesthesia recommends that anesthesiologists should be aware of the limitations of the physical exam to determine the puncture level, especially in patients with difficult topographic anatomy. Pregnant and obese patients are included among those ${ }^{4}$. It has been demonstrated that obesity during pregnancy increases the incidence of maternal-fetal complications and the prevalence of cesarean sections ${ }^{5}$.

The use of the ultrasound in anesthesiology has been increasing, and its use has been proposed to determine the puncture level for spinal blocks ${ }^{6}$.

The objective of this study was to determine whether identification of the $L_{3}-L_{4}$ space by the physical exam differs from that of the ultrasound in obese and non-obese pregnant women.

\section{METHODS}

After approval by the Local Ethics on Human Research Committee and signing of an informed consent by the patients, this prospective study was undertaken. Inclusion criteria were as follows: 18 years of age or older, eight-hour fasting, and elective cesarean section for term pregnancy under subarachnoid block. Exclusion criteria were: twin pregnancy, contraindication to subarachnoid block (infection at the puncture site, coagulopathy, patient refusal, increased intracranial pressure, 
abnormal spinal anatomy, or hypertension), and patients undergoing urgent or emergency cesarean sections.

Patients were monitored with pulse oximeter, non-invasive blood pressure, and cardioscope on $D_{\|}$derivation, and venous access was established on an upper limb.

With the patient in the sitting position, an anesthesiologist with more than five years of experience in obstetric anesthesia indentified the $L_{3}-L_{4}$ space using anatomical references, i.e., the level that an imaginary line connecting both upper iliac crests crossed the spine identified $L_{4}$ or the $L_{4}-L_{5}$ space. This was followed by lumbar ultrasound with a SonoAce 8000 EX Prime (Medison Co., Seoul, South Korea). A convex transducer of 2-5 MHz was used. The transducer was initially placed on the sacral region on a longitudinal paramedian presentation, 2 to $3 \mathrm{~cm}$ from the midline, angled to the center of the spinal canal. The sacrum was identified as a continuous hyperechoic line. The transducer was directed cranially, identifying the spinous processes of the lumbar vertebrae as a saw-like image in which the teeth of the saw represent the processes and the valleys correspond to the intervertebral spaces (Figure 1) ${ }^{7}$. After ultrasonographic identification of the intervertebral spaces, the level of the clinically estimated $L_{3}-L_{4}$ space was recorded. Lumbar puncture was performed on the $L_{3}-L_{4}$ space, identified by ultrasound using the median approach, with a 26G Quincke needle; $10 \mathrm{mg}$ of $0.5 \%$ hyperbaric bupivacaine associated with $80 \mu \mathrm{g}$ of morphine were administered, and the anesthesia followed the protocol of the institution.

The degree of obesity was determined according to the classification of the Body Mass Index (BMI) of the World Health Organization, which is adopted by the American College of Obstetrics for pregnant patients.

Patients' data were analyzed in two groups: Group 1 (G1), non-obese patients with BMI lower than $30 \mathrm{~kg} \cdot \mathrm{m}^{-2}$, and Group 2 (G2), obese patients with BMI equal or greater than 30 $\mathrm{kg} \cdot \mathrm{m}^{-2}$.

To detect a $27 \%$ difference in the accuracy of the clinicallyestimated puncture levels between obese and non-obese

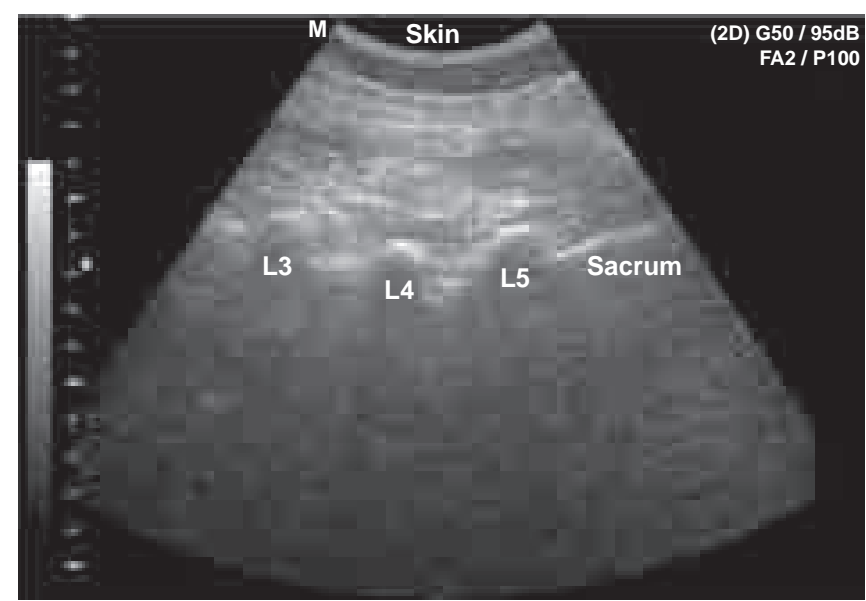

Figure 1 - Longitudinal ultrasound of the lumbosacral region identifying the upper portion of the sacrum and spinous processes of the lumbar vertebrae. patients, with proportion analysis test - accepting a 5\% alpha error and $20 \%$ beta error - the size of de study population was calculated as 40 patients per group. We considered a prior study ${ }^{8}$ that estimated the percentage of the correct clinical identification of the puncture level around $40 \%$. Data were stored in a data bank of the Microsoft Office Excel v. 7.0 (Seattle, 2003). Afterwards, the Analysis - Epi Info v 3.3.2 software (CDC 2005) was used for statistical analysis. The level of statistical significance was $95 \%$.

Data are presented as mean \pm standard deviation or absolute frequency (percentage). The Chi-square test was used to determine the intergroup association among qualitative parameters. The Student $t$ test was used for intragroup differences in quantitative parameters.

\section{RESULTS}

From August 2008 to April 2009, 90 patients were included in the study, 43 patients in G1 (non-obese) and 47 in G2 (obese). Table I shows the demographic data.

Lumbar intervertebral spaces were identified and counted by ultrasound in all patients. Table II shows the intervertebral spaces identified as $L_{3}-L_{4}$ on physical exam and the corresponding space on ultrasound. A wide variation, without statistically significant differences, was observed.

Temporary or permanent neurologic symptoms related with the spinal block were not observed.

Table I - Demographic Data

\begin{tabular}{lccr}
\hline & $\begin{array}{c}\text { Group 1 } \\
\text { non-obese }\end{array}$ & $\begin{array}{c}\text { Group 2 } \\
\text { obese }\end{array}$ & P \\
\hline Age (years) & $28.16 \pm 7.15$ & $29.60 \pm 6.24$ & 0.313 \\
BMl (kg.m ${ }^{-2}$ ) & $26.58 \pm 2.08$ & $34.39 \pm 3.68$ & $<0.001$ \\
Gestational age (weeks) & $39.40 \pm 1.31$ & $39.11 \pm 1.45$ & 0.325 \\
\hline
\end{tabular}

BMI - Body mass index; Student $t$ test.

Table II - Ultrasound Determination of the Intervertebral Space Clinically Identified as $L_{3}-L_{4}$

\begin{tabular}{lccc}
\hline & $\begin{array}{c}\text { Group 1 } \\
\text { non-obese }\end{array}$ & $\begin{array}{c}\text { Group 2 } \\
\text { obese }\end{array}$ & $P$ \\
\hline $\mathrm{L}_{1}-\mathrm{L}_{2}$ & $3(7 \%)$ & $2(4 \%)$ & 0.186 \\
$\mathrm{~L}_{2}-\mathrm{L}_{3}$ & $14(33 \%)$ & $22(47 \%)$ & \\
$\mathrm{L}_{3}-\mathrm{L}_{4}$ & $23(53 \%)$ & $23(49 \%)$ & \\
$\mathrm{L}_{4}-\mathrm{L}_{5}$ & $3(7 \%)$ & $0(0 \%)$ & \\
\hline
\end{tabular}

Chi-square test.

\section{DISCUSSION}

The results of the present study are in agreement with those reported in the literature, which have demonstrated that based 
only on topographic anatomy the level of accuracy of anesthesiologists to identify lumbar intervertebral spaces ranges from $29 \%$ to $41 \% 3,9,10$. Mistaken identifications are usually in the cephalad direction, and the difference can be up to four spaces $^{9}$. Those differences can be explained by two reasons.

First, most anthropometric parameters have a normal distribution, i.e., a central peak that becomes progressively smaller the farther it is from the mean. This is valid for Tuffier's line and it has been demonstrated radiologically and in cadavers that this line can vary from the $L_{5}-S_{1}$ to $L_{3}-L_{4}{ }^{11}$. Second, the position of the patient during the physical exam and $X$ ray or MRI differs, and most imaging exams are performed with the patient in the supine position. It has been suggested that the $L_{4}-L_{5}$ distance can increase up to $1 \mathrm{~cm}$ when the patient is bent ${ }^{12}$.

In 2002, Furness demonstrated that the ultrasound could be used to identify the intervertebral spaces ${ }^{13}$. He used the ultrasound image in the midline to identify the sacrum and spinous processes of the lumbar vertebrae and compared 45 estimates of the intervertebral space. An $84 \%$ accuracy in the ultrasound identification against only $37 \%$ by palpation was identified.

More recently, two retrospective studies ${ }^{8,14}$ compared physical exam and ultrasound in obstetric patients. Both evaluated patients in the puerperium, using the epidural or subarachnoid puncture marks for cesarean section or labor analgesia. The authors reported concordance rates of $55.0 \%$ and $55 \%$ between the vertebral spaces attributed by the anesthesiologist and that of the ultrasound. Once more, the error of the anesthesiologists varied from one to two cephalad segments. None of the authors observed differences in the correct identification of the intervertebral space when the weight of the patients was analyzed. Those studies can be criticized because post-partum changes in the body of pregnant patients can be seen, therefore explaining possible differences between the blockade and the ultrasound.

This is the difference between the present study and previous studies: performing the ultrasound before the blockade and the delivery and both in the same position. Although concordance rates similar to those reported in the literature were observed - 53\% in G1 and $49 \%$ in $\mathrm{G} 2$ - punctures were performed in the $L_{3}-L_{4}$ space determined by ultrasound. Our study also analyzed patients in two groups according to the BMI, and the lack of differences between both groups in the concordance rate of the identification of the $L_{3}-L_{4}$ space were not surprising.

The position of the medullary cone also follows normal distribution. In one study that analyzed $635 \mathrm{MRI}$ images, the mean level of the medullary cone was identified at the mid-third of $L_{1}$, but it varied from the mid-third of $T_{12}$ to the upper third of $L_{3}$. This study also observed gender- and age-related differences in the anatomy of the medullary cone. The level of the medullary cone was lower in females and in the elderly ${ }^{15}$.

An important study by Reynolds ${ }^{16}$ reported a series of seven cases of neurological damage in spinal or combine block. All patients were females, and six were obstetric cases. Penciltip needles were used in all patients and the anesthesiologist believed he was puncturing the $L_{2}-L_{3}$ space. Magnetic resonance imaging demonstrated spinal cord lesion at the level of $T_{12}$, in five patients, and $L_{1}$ in one. It also demonstrated that none of the patients had an abnormally long medullary cone. Patients complained of paresthesia during the blockade, but only one complained of pain during the administration of the anesthetic.

The mechanism proposed for the lesion was direct needle trauma to the medullary cone. It was also suggested that, besides the mistaken identification of the intervertebral space, non-traumatic needles were associated with higher probability of neurologic damage, because one millimeter of the needle penetrates in the subarachnoid space before the backflow of CSF. Those data reinforce the idea that the $L_{2}-L_{3}$ space is not adequate for lumbar puncture.

However, even the correct identification of the $L_{3}-L_{4}$ space does not exclude the risk of neurologic damage of the medullary cone. The case of a patient who developed "dropped foot" after subarachnoid block in $L_{3}-L_{4}$ for cesarean section ${ }^{17}$ has been reported. Lumbar MRI showed that the medullary cone of that patient reached the level of $L_{4}$. Symptoms of medullary cone and cauda equina lesions include lumbar pain, pain in the lower limbs, paresthesia, and sphincter dysfunction. The incidence of neurologic lesions after subarachnoid block has been estimated in six out of every 10,000 anesthetic procedures, with permanent damage in less than one in $10,000^{18}$.

Limitations for the use of the ultrasound include learning the ultrasonographic anatomy, cost, time for execution, and technical limitations, since it is an operator-dependent exam. However, it has been proposed that with increased clinical experience many of these disadvantages can be overcome and it will be possible to increase the reliability of the method ${ }^{7}$. Note that the ultrasound is not the gold standard for the determination of the level of intervertebral puncture and identification errors can still be made. For this reason, current care with paresthesia and pain during neuroaxis blocks are still valid.

Summarizing, the rate of the correct identification of the $L_{3}-L_{4}$ space in pregnant women by clinical evaluation is low, both in obese and non-obese pregnant women. Spinal ultrasound before the blockade can reduce the rate of mistaken identification of the $L_{3}-L_{4}$ space in both groups. Further studies to determine whether the use of the ultrasound to determine the level of the lumbar puncture in pregnant women decreases the risk of medullary cone damage during subarachnoid block are necessary.

\section{REFERÊNCIAS - REFERENCES}

1. Tsen LC. Anesthesia for cesarean delivery. ASA Refresher Courses Anesthesiol 2005;33:235-245.

2. American Society of AnesthesiologistsTask Force on Obstetric Anesthesia. Practice guidelines for obstetric anesthesia: an update report. Anesthesiology 2007;106:843-2863.

3. Van Gessel EF, Forster A, Gamulin Z. Continuous spinal anesthesia: where do spinal catheters go? Anesth Analg 1993;76:1004-1007.

4. Neal JM, Bernards CM, Hadzic A et al- ASRA Practice advisory on neurologic complications in regional anesthesia and pain medicine. Reg Anesth Pain Med 2008; 33:404-415. 
5. Baeten JM, Bukusi EA, Lambe M. Pregnancy complications and outcomes among overweight and obese nulliparous women. Am J Public Health 2001;91:436-440.

6. Watson MJ, Evans S, Thorp JM. Could ultrasonography be used by an anaesthetist to identify a specified lumbar interspace before spinal anaesthesia? Br J Anaesth 2003;90:509-511.

7. Carvalho JCA. Ultrasound-facilitated epidurals and spinals in obstetrics. Anesthesiology Clin 2008;26:145-158.

8. Schlotterbeck H, Schaeffer R, Dow WA et al. Ultrasonographic control of the puncture level for lumbar neuraxial block in obstetric anaesthesia. Br J Anaesth 2008;100:230-234.

9. Broadbent CR, Maxwell WB, Ferrie R et al. Ability of anaesthetists to identify a marked lumbar interspace. Anaesthesia 2000;55:1122-1126.

10. levins FA. Accuracy of placement of extradural needles in the L3-4 interspace: comparison of two methods of identifying L4. Brit J Anaesth 1991;66:381-382.

11. Hogan QN. Tuffier's line: the normal distribution of anatomic parameters. Anesth Analg 1994;78:194-195.

12. Thavasothy $M$. The reproducibility of the iliac crest as a marker of lumbar spinal level. Anaesthesia 1997;52:811.

13. Furness G, Reilly MP, Kuchi S. An evaluation of ultrasound imaging for identification of lumbar intervertebral level. Anaesthesia 2002;57:277-280.

14. Whitty $R$, Moore $M$, Macarthur A. Identification of the lumbar interspinous spaces: palpation versus ultrasound. Anesth Analg 2008;106:538-540.

15. Soleiman J, Demaerel P, Rocher $S$ et al. Magnetic resonance imaging study of the level of termination of the conus medullaris and the thecal sac: influence of age and gender. Spine 2005;30:1875-1880.

16. Reynolds F. Damage to the conus medullaris following spinal anaesthesia. Anaesthesia 2001;56:238-247.

17. Ahmad FU, Pandey P, Sharma BS et al. Foot drop after spinal anesthesia in a patient with a low-lying cord. Int J Obstet Anesth 2006; 15:233-236.

18. Auroy $Y$, Narchi $P$, Messiah A et al. Serious complications related to regional anesthesia: results of a prospective survey in France. Anesthesiology 1997;87:479-486.

\section{RESUMEN}

Locks GF, Almeida MCS, Pereira AA - Uso del Ultrasonido para Determinación del Nivel de Punción Lumbar en Embarazadas.

JUSTIFICATIVA Y OBJETIVOS: Para determinar el nivel vertebral para la punción lumbar, se utiliza una línea imaginaria que une las crestas ilíacas. Esa línea cruza la columna vertebral en el nivel $L_{4}$ o en el espacio $L_{4}-L_{5}$. Esa referencia anatómica puede ser inexacta en una gran proporción de pacientes. Este estudio quiso determinar si existe alguna diferencia en la determinación del espacio vertebral $L_{3}-L_{4}$ por el examen físico cuando se le comparó al ultrasonido en embarazadas obesas y no obesas.

MÉTODO: Se estudiaron pacientes adultas sometidas a la cesárea electiva bajo raquianestesia. Las pacientes se analizaron en dos grupos: obesas y no obesas. Con la paciente en la posición sentada, se determinó a través del examen físico, el espacio vertebral $L_{3}-L_{4}$. Enseguida se realizó el ultrasonido de la región lumbar. Se identificó el hueso sacro y el transductor fue colocado en dirección craneal para identificar los procesos espinosos de las vértebras lumbares. Quedó registrado el nivel vertebral que había sido estimado clínicamente como $L_{3}-L_{4}$.

RESULTADOS: Se incluyeron 90 pacientes, siendo 43 no obesas y 47 obesas. En todas las pacientes se pudieron determinar los espacios vertebrales lumbares a través del ultrasonido. Los espacios vertebrales identificados como $L_{3}-L_{4}$ en el examen físico, correspondieron a los estimados como $L_{3}-L_{4}$ por el ultrasonido en un 53 y un $49 \%$ en los grupos de no obesas y obesas, respectivamente. No hubo diferencia significativa entre los grupos.

CONCLUSIONES: El porcentaje de acierto en la identificación del espacio vertebral $L_{3}-L_{4}$ en embarazadas obesas y no obesas es bajo. El ultrasonido de la columna vertebral puede reducir el error de determinación del espacio vertebral $L_{3}-L_{4}$ en embarazadas obesas y no obesas. 